\title{
TOKOH UTAMA DALAM KEHANCURAN DI BARUH KELAYAR
}

\author{
Jamilah \\ Universitas Terbuka Banjarmasin \\ email: jamilah-bjm@ecampus.ut.ac.id
}

\begin{abstract}
ABSTRAK
Peneliti ini mengkaji tentang kepribadian tokoh utama dalam cerita rakyat kehancuran di baruh kelayar karya Anggraini Antemas telaah psikologi. Tujuan penelitian ini adalah untuk: (1) Mendeskripsikan kondisi kepribadian tokoh utama dalam cerita rakyat Kehancuran di Baruh Kelayar karya Anggraini Antemas, (2) mendeskripsikan proses kepribadian tokoh utama dalam Kehancuran di Baruh Kelayar karya Anggraini Antemas.

Pendekatan yang digunakan dalam penelitian ini adalah pendekatan psikologi. Metode yang digunakan dalam penelitian ini dalah metode deskrptif analisis. Sumber data penelitian ini adalah cerita rakyat Kehancuran di Baruh Kelayar karya Anggraini Antemas. Cerita rakyat ini merupakan yang diterbitkan Ananda Nusantara (AN), Amuntai tahun 2016 dengan tebal 107 halaman. Teknik yang digunakan dalam mengumpulkan data dalam penelitian ini adalah teknik dokumentasi kepustakaan, dan teknik analisis data yang digunakan adalah teknik, deskriptif.

Hasil penelitian dapat disumpulkan sebagai berikut: Gambaran kepribadian tokoh utama dalam cerita rakyat Kehancuran di Baruhelaya karya Anggraini Antemas meliputi: (a) kondisi kepribadian suka memancing di danau didekat rumahnya (b) diasuh oleh mahkluk gaib dari dasar danau dian tokoh meliputi (1) kedewasaan jasmani meliputi (a) terjadinya cobaan sakitnya saorang anak (b) menyapu air mata dengan selendang (c) perahu meluncur seperti anak panah. (2) kedewasaan intelektual (a) Marilah kita ke istana (b) bawalah aku ketempatmu (c) Dapatlah mempertimbangkan permohonan kami (d) Kami setuju pernikahan kami di batalkan (3) kedewasaan emosional (a) belum berputus asa (b) masih meminta dengan suara yang rendah dan beriba-iba (c) Dengan muka yang juga mengentupkan giginya (d) Keduannya saling berpandangan muka yang merah.Gambaran proses kepribadian tokoh utama dalam cerita rakyat Kehancuran di Baruh Kelayar karya Anggraini Antemas meliputi: a) masa kanak-kanak (1) suka memancing di danau didekat rumahnya (2) diasuh oleh mahkluk gaib dari dasar danau (b) masa remaja meliputi (1) Makin besar makin cantik parasnya (2) mengganggu ketentraman keluarga pak Rombi (c) masa dewasa meliputi (1) istana sulakarta sangat bergembira menyambut hari perkawinan angung putera mahkota (2) sesuduh dinikahkan mareka diarak keliling kampung.
\end{abstract}

Kata Kunci: tokoh utama, cerita rakyat, psikologi sastra

\section{PENDAHULUAN}

Karya sastra merupakan hasil perpaduan harmonis antara kerja sama perasaan dan pikiran. Di dalamnya penuh makna dan fungsi, Makna dan fungsi ini sering kebur dan tak jelas. Karena, karya sastra memang syarat dengan imajinasi. Itulah sebabnya, penelitian sastra memiliki tugas untuk mengungkap kekaburan itu menjadi jelas. Penelitian sastra akan mengungkap elemen-elemen dasar pembentuk sastra dan menafsirkan sesuai paradigma atau teori yang digunakan sebagai cermin 
kehidupan manusia, karya sastra mampu membuat pembaca membayangkan dan menghayati pengalaman hidup manusia sewajarnya. Salah satu masalah yang dialami manusia adalah psikologi. Setiap orang mengalami fenomena kejiwaan dalam diri yang berbeda-beda. Oleh karena itu, pengarang menggunakan tokoh-tokoh untuk menunjukkan fenomena kejiwaan yang dialami oleh seseorang.

Fenomena kemanusiaan yang komplek, ada peristiwa suka, duka dan sebagai peristiwa hidup lainnya. Semua itu merupakan hasil ciptaan konflik mempengaruhi kehidupan manusia seperti pikiran, perasaan, tingkah laku seseorang yang beradaptasi dalam kehidupan. Pembawaan yang mencakup dalam pikiran, perasaan, dan tingkah laku merupakan karakteristik seseorang yang menampilakan cara ia beradaptasi dan berkompromi dalam kehidupan disebut juga dengan kepribadian.

"Pada dasarnya, paikologi sastra mempunyai empat kemungkinan pengertian. Pertama adalah studi psikologi pengarang sebagai tipe atau sebagai pribadi; kedua adalah sebagai studi kreatif; ketiga, studi tipe dan hukum-hukum psikologi yang diterapkan pada karya satra; keempat, memplajari dampak sastra pada pembaca'” (Endraswara, 2008:64).

Kata "kepribadian (personality) berasal dari kata latin: persona. Pada mulanya, kata persona ini menunjuk pada topeng yang biasa digunakan oleh pemain sandiwara di zaman dalam memainkan peranan-peranannya. Lambat-laun, kata persona (personality) berubah menjadi satu istilah yang mengacu pada gambaran sosial tertentu yang diterima oleh individu dari kelompok atau masyarakatnya, kemudian individu tersebut diharapkan bertingkah laku berdasarkan atau sesuai dengan gambaran sosial (peran) yang diterimanya (Koswara, 1991:10).

Dalam menelaah karya sastra digunakan beragam pendekatan. Pendekatan itu sangat tergantung dari arah mana memandang suatu karya sastra tersebut. Sekarang ini dikenal pendekatan struktural, resepsi, ekspresif, sosiologi, psikologi, dan objektif. Pendekataan psikologi digunakan dalam penelitian ini karena psikologi dan karya sastra saling berkaitan, bila kita ingin melihat dan mengenal manusia di perlukan psikologi.Apabila manusia sering mengalami konflik kejiwaan yang bermula dari sikap kepribadian tertentu serta berdampak pada permasalahan kejiwaan

Pada cerita rakyat Kehancuran di Baruh Kelayar karya Anggraini Antemas yang diterbitkan pertama kali oleh Ananda Nusantara, Amuntai, 2016. Cerita rakyat Kehancuran di Baruh Kelayar ini mempunyai tebal 107 halaman yang menceritakan kisat rakyat di desa Baruh Bahinu, Kecamatan Awayan. Dalam cerita ini pengarang menciptakan pamahaman tentang perspektif dari mana hubungan antara dunia atau alam gaib, yang lebih menarik minat peneliti untuk meneliticerita 
ini ialah bagaimana pengarang menciptakan cerita yang membuat peneliti tercengang, tersentuh, ketakutan, merenung, dan tersenyum.

Pada cerita rakya Kehancuran di BaruhKelayarkarya Anggraini Antemas. Ada satu keluarga Pak Rombi dan anaknya yang bernama Endang Mas satu kelurga ini hidup di sekitar danau Kelayar terdapat suatu kerajaan, bernama Sulakarta dengan Rajanya bernama Temanggung Narodipa. "Pada suatu hari Endang Mas membantu ayahnya yang sedang di kebun kemudian ia bertemu seorang laki-laki yang bernana Awang Sura. Pada pertemuan yang pertama ini Endang Mas jatuh cinta kepada Awang Sura". Dengan berjalannya waktu mereka berdua melanjutkan keplaminan, dalam percintaan mereka berdua tak semudah membalikan telapak tangan, pada waktu itu mereka mengalami cobaan-cobaan yang berat sampai-sampai nyawa meraka berdua pun menjadi taruhannya."Pada suatu hari Endang Mas mengalami gangungan dari mahkluk gaib.

Mengenai penelitian kepribadian, sebelumnya telah dilakukan oleh Ahmad Rifqi Syaida (2016) dengan judul "Kepribadian Tokoh Utama dalam Novel Moga Bunda Disayang Allah karya Tere Liye kajian Psikologi Satra', Pada penelitian tersebut ia menyimpulkan bahwa kepribadian tokoh adalah suatu sikap yang diperankan oleh setiap tokoh satu cerita.

Bedasarkan uraian tersebut peneliti tertarik menelaah cerita rakyat Kehancuran di Baruh Kelayar, karena ceritanya sangat menarik, yakni masalah tentang kejiwaan seorang tokoh yang mempunyai depresi sehingga kejiwaannya terganggu, cerita ini merupakan suatu pelajarandan masukan agar kita tidak terjerumus ke dalam kehidupan yang salah. Dan peneliti ingin mengkaji lebih dalam lagi terhadap kepribadian tokoh utama cerita rakya dengan kepribadian tokoh utama dalam cerita rakyat Kehancuran di Baruh Kelayar karya Anggraini Antemas. Karena dalam buku tersebut banyak terdapat masalah kehidupan yang terjadi dalam tokoh utama tersebut. Dengan telaah tersebut diharapkan peneliti mampu memperoleh gambaran mengenai masalah psikologi yang di alami tokoh utama pada cerita tersebut.

\section{METODE}

Guna mendapatkan gambaran mengenai pendekatan dan jenis penelitian yang digunakan, maka berikut ini disajikan landasan teori pendukung tentang pendekatan dan jenis penelitian yang meliputi: 1) pendekatan penelitian, dan 2) jenis penelitian.

Pada penelitian yang berjudul Kepribadian Tokoh Utama Dalam Cerita Rakyat Kehancuran di Baruh Kelayar karya Anggraini Antemas, peneliti menggunakan pendekatan psikologis. Pendekatan psikologis lebih dekat dengan pendekatan biografis dibandingkan dengan pendekatan 
sosiologis sebab analisis yang dilakukan cenderung memanfaatkan data-data personal. Proses kreatif merupakan salah satu model yang banyak dibicarakan dalam rangka pendekatan psikologis. Karya sastra dianggap sebagai hasil aktivitas penulis yang sering dikaitkan dengan gejala-gejala kejiwaan, seperti: obsesi, kontemplasi, kompensasi, sublimasi, bahkan sebagai neurosis (Ratna, 2004: 62-63).

\section{HASIL DAN PEMBAHASAN}

\section{Cerita Rakyat Kehancuran di Baruh Kalayar Karya Anggraini Antemas}

\section{Sinopsis}

Pada beberapa abad yang lalu disekita danau kelayar ada terdapat sebuah kerajaan, bernama Sulakarta dengan Rajanya bernama Temenggung Narodipa, dan dipinggir danau tersebut berdiamlah satu kelurga nelayan, yaitu Pak Rombi namanya, bersama istri dan anaknya perempuan. Rombi adalah anak laki-laki yang sudah meninggal beberapa tahun lalu. Namun sebutan tersebut tetap melekat kepada sebutan pada Pak nelayan itu rupanya sudah menjadi kebiasaan memanggil dengan sebutan anak tersebut. Pekerjan Pak Rombi selain menangkap ikan ia juga bertani padi dan sayuran serta buah-buahan untuk keperluan sehari-hari. Sejak anak Pak Rombi beranjak dewasa, ia sering sekali membantu ayahnya di kebun memetik hasil tanaman untuk dimakan. Suatu ketika ada pemuda datang untuk membeli buah hasil tanamanPak Rombi tadi pada ketika pemuda itu melihat anak Pak Rombi yang sedang membantu memetik buah pemuda ini lalu si Indang Mas memandang pemuda tersebut matanya tertuju kesegala arah, maklum bunga yang baru mekar. Setiap laki-laki yang memandang wajah cantiknya Indang Mas pasti jatuh cinta, dan rasa ingin memiliknya. Pada suatu hari pemuda yang bernama Awang sura ingin mengajak Indang Mas untuk memancing di danau yang terkenal angker itu. Lalu Indang Mas meminta izin dari kedua orang tuanya itu, mareka berdua izinkan untuk memancing di danau Kelayar, drngan menggunakan perahu kecil. Kedua pasangan itu terasa bisa berdua canda tawa tak berhenti yang dilakukan kedua kekasih tersebut.

\section{Analisis Kondisi Kepribadian Tokoh Utama Cerita Rakyat Kehancuran di Baruh Kelayar Karya Anggraini Antemas}

\section{a. Kedewasan Jasmani}

Orang sudah dewasa secara jasmani bila ukuran, berat, kekuatan, keterampilan, dan koordinasinya sudah cukup, sesuai dengan umur dan jenisnya. Perlu diingat bahwa kedewasaan 
jasmani tidak bergantung pada tinggi dan berat tubuhnya, tetapi tumbuh normal secara jasmani dalam corak dan bentuk masing-masing sesuai dengan hokum alam.

Kutipan [1]

"Sejak dahulupun aku sudah mengira demikian, nak Sura. Ada suatu yang gaib terjadi pada sakit si Indangn. Telah banyak kucoba meminta bantuan dukun yang ampuh, tetapi belum seorangpun yang bisa menyembuhkan. Ah..kasihan, si Indang” Pak Rombi mengeluh dengan setetes air mata mengantung di bula matannya. Istri pak Rombi pun sejak tadi menangis dan menyapu air mata dengan selendangnya. Perempuan tua ini duduk bersimpuh di samping pembariangan anaknya si Indang yang sudah semakin kurus dan telah kehilangan keayuannya itu. Ibu tua inipun rupanya sependiarian dengan suaminya, mearasa amat berat untuk meninggalkan kampung halamannya, tepian danau, gubuk tua yang telah banyak memberikan warna kehidupan di dusun tersebut. (KB. KK hal 25)

Kutipan [1] menunjukan bahwa pengertian mengenai kedewasaan pada tokoh utama pak Rombi dan istri mempunyai kekuatan dalam hati yang di maksud.kekuataan dalam hati ialah mentabahkan hatinya dapat menerima cobaan pada anaknya. Kutipan [1] membuktikan bahwa pak Rombi sama istrinya kuat dan tabah menerima cobaan yang di alami dalam keluarga meraka tersebut.

Kutipan [2]

Berdesau-desau bunyi pengayuh Awang Sura membelah air. Percikan air telah membasahi pakaian Indang Mas dan pakaiannya sendiri. Dan perahu kecil tersebut meluncur bagaikan anak panah lepas dari busurnya, ingin melepaskan diri dari putaran pulau yang semakain kencang bagaimana kincir angin. Perahu Awang yang telah didayungnya sekuat tenaga untuk mencapai dataran di tepi danau tersebut. (KB. KK hal 7)

Kutipan [2] juga menunjukan bahwan kedewasaan jasmani pada tokoh utama Awang Sura ia mempunyai kekuatan yang yang tidak semua orang mempunyai kekuatan yang sama dirinya. Pada kutipan [2] ini membuktikan pada Awang Sura mendayung perahunya dengan sangat kencang seperti anak panah yang lepas dari busurnya. Maka dari itu Awang memiliki kekuatan yang lebih dari orang lain.

\section{b. Kedewasaan Intelektual}

Kedewasaan intektual adalah seseorang dapat dikatakan dewasa secara intelektual apabila iya mampu berpikir secara matang dan logis, mempunyai pertimbangan tepat, dan pengertian mengenai dunia serta diri sendiri.

\section{Kutipan [3]}

Indang menangis sambil mencari-cari lengan ibunya, suaranya mendesir di antara bibir yang pucat pasi, tapi masih jelas lekuk-lekuk kemungilannya. Bu..aku ingin 
mendengar dari kak Awang sendiri, apakah ia benar-benar ingin menyembuhkan aku. Mendengar kata Indang, Awang mendekati Indang Mas dan berkata dengan penuh harap. Kak awang apakah kakak benar-benar ingin aku sembuh, tak usah kau ragukan lagi Indang Mas demi keselamatanmu aku akan bersedia berkorban. Marilah kita ke istana, sekarang juga. Kakak tidak akan menyia-nyiakan aku di istana, bawalah aku ketempatmu. Keduanya bepegangan tangan, seperti tak ingin berpisah lagi. Dan mareka rupanya tak menyadari bahwa perbuatannya itu dilakukan di hadapan keduan orang tuanya, pak Rombi dan istrinya. (KB. KK hal 27-28)

Kutipan [3] menunjukan bahwa tokoh utama Indang Mas berpikir secara matang dan logis. Kutipan [3] menggambar bagaimana sikap Indang Mas kepada Awang Sura kekasihnya tanpa pikir panjang iya menerima tawaraan dari Awang pergi ke istana untuk mengobati penyakitnya. Dan tanpa di sadari kedua pasangan tersebut berpegangan tangan yang bukan muhrimnya, seakan-akan mareka tak pedulia di lihat oleh pak Rombi dan istrinya.

Kutipan [4]

Pak lingkur dan rombungannya pergi kesebuah danau yang angker penguasa danau tersebut adalah Mira Nagasakti dan Arya Laksana. Datanglah penguasa danau tersebut dan berkata, apa maksud kalian datang kemari.? Maksud kami baik sahut pak Lingkur. Kami pertam-tama mempersembahkan sesajin dan maksud kami datang kemari memohon kemurahan hati kepada Datuk Nagasakti, agar Awang Sura dan Indang Mas yang sedang bertunangan. Hindarkanlah gangguan-gangguan terhadap kedua cucu kami ini Datuk. Berikanlah kesembuhan atas penyakitnya, sehingga mereka bisa kawin. Datuk Nagasakti pun menolak pemintaan

Dapatlah datuk mempertimbangkan permohonan kami. Baretnya lagi Pak Lingkur. Sambil mengelurkan senjata andalannya yaitu bambu batulis, Kemudian Datuk Mira Nagasakti pun terkejut dengan senjata yang dibawa Pak Lingkur. Lalu Datuk berkatajika itu permintaan kalian baiklah. Kami setuju perkawinan Arya Laksana dengan Indang Mas dibatalkan saja.

Kutipan [4] menunjukan bahwa tokoh utama pada Mira Nagasakti mempunyai pertimbangan tepat. Pada kutipan [4] ini dapat di buktikan tokoh utama pada Mira Nagasakti yang tadi keras hati ingin menjodohkan anaknya sendiri dengan Indang Mas. Datuk pun mempertimbangkan kembali bahwa dunia nyata dengan dunia gaib ini berbeda maka dari itu Datuk Nagasakti mengijinkan Awang Sura dan Indang Mas ini menikah, dengan satu syarat sebagai penggantinya Datuk meminta sepasang kambing putih, dan Pak Lingkur memenuhi syarat itu tersebut.

Kutipan [5]

Sehari sebelum upacara perkawinan, dukun tua pak Lingkur dan beberapa orang pengiring pilihan telah memerlukan lagi ke pulau Pulantan yang angker itu, untuk mengantar sepasang kambing putih jantan-betina, memenuhi janji sajian Datuk Mira Nagasakti

Mareka datang menepati janji untuk menyerahkan "tebusan". Dengan "tebusan" itu Pak Lingkur mengharap, semoga perkawinan Indang Mas dengan Awang Sura mendapat restu dan tidak diganggu kacaukan lagi oleh roh-roh gaib di dasar danau tersebut. 
Akhirnya hari-hari yang ditunggukan dating juga, putra mahkotan Awang Sura bersama gadis Indang Mas, dua sejoli yang cantik rupan bagai pinang dibelah dua, setelah seminggu yang terakhir ini dimandikan, didudus dengan wangi-wangian, alat kecantikan pusaka bahari, sudang bareng tentukeduannya menjadi lebih cantik laksan bidadari-bidadari turun dari kayangan atau nerwana.

Sesudah merika dinikahkan secara adat, dan setelah kedua mempelai bersujud kepada kedua ibu bapaknya masing-masing (Temanggu Narodipa Pak Rombi beserta istrinya), lalu dinaikkanlah mereka ke dalam kendaraan kencana yang ditarikoleh dua ekor kuda putih, dibawa keluar keratin. Acara ini dilakukan, selain daripada melaksanakan adat leluruh zaman bahari yang dianut turun temurun juga adalah untuk memenuhi permintaan seluruh lapisan masyarakat Sulakarta, yang memohon kedua mempelai diarak keliling kota, melewatkan lautan manusia yang mencintai putera mahkota kerajaan kesayangan itu. (KB. KK hal 73-74)

Kutipan [5] menunjukan bahwa pengertian mengenai dunia serta diri sediri, kutipan [5] ini dapat dilahat bahwa di dunia ini tidak hanya manusia, binatang, tumbuhan saja tetapi di dunia ini ada mahkluk yang tak kesat mata tinggal di dunia ini. Seperti halnya dengan pak Lingkur menginginkan Awang Sura dan Indang Mas dalam pernikahannya berjalan dengan aman dan nyaman.

\section{c. Kedewasaan Emosional}

Kedewasaan emosional umumnya mempunyai segi rangkap, yakni segi positif dan segi negatif. Dalam segi positif kita mampu mengungkapkan pererasaan kita secara tepat. Dan segi negatif kita wajib mengatur perasaan kita, sehingga mengungkapkannya tidak mengganggu perkembangan kita atau melukai orang lain.

Kutipan [6]

Pak Lingkur belum berputus asa. Ia masih minta dengan suara rendah dan beribaiba. Tetpi wahai bapak Datuk Mira Nagasakti, junjungan kami. Bukanlah Arya Laksana dengan Indang Mas itu ia berdua saudara kandung. Hemmm..itu benar. Dulunnya Arya Laksana kakaknya dari Indang Mas selagi dia orang dunia. Tapi sekarang, Arya laksana sudah masuk warga kami di alam gaib dibawah samudera, Arya Laksana tak kenal lagi siapapun di dunia, kecuali dia mencintai gadis Indang Mas yang pertama kali dilihatnya menginjak masa remaja.

Pak Lingkur merasa sudah tiba saatnya dia harus menguasai keadaan yang tenang itu. Dan memang, setelah terpegangnya bambu runcing tiga ruas di tangan dukun tersebut, maka jelas kelihatan pak Lingkur menjadi lebih menempakan kewibawaaannya

Pada kutipan [6] di atas bahwa kedewasaan emosi segi positif, mampu mengungkapkan perasaan kita secara tepat, dalam situasi yang tepat. Kutipan [6] di atas menggambarkan bahwa emosi yang di keluarkan Datuk Mira Nagasakti bisa di bendung oleh Pak Lingkur dan bisa bicarakan tanpa adanya kekerasan. 
Kutipan [7]

Indang Mas akan dikawinkan dengan Awang Sura.? Haa.tidak bisa, tidak bisa. Indang Mas sudah aku pinang buat istri anakku sendiri si Arya Laksana. Demikian jawab Mira Nagasakti dengan angkuhnya. Matanya memandang kepada Arya Laksana di sampingnya.

Bisakah datuk....atas permohonan kami Indang Mas akan dikawinkan dengan Awang Sura dari Keraton Sulakarta Haaa, hahaaa...apa yang sudah aku tetapkan, tidak bisa dirubah oleh siapapun. Dalam istanaku di bawah laut. Si Indang Mas akan kujadikan putri mahkota. Dia akan lebih bahagia daripada dikeraton Sulakarta....haaa...tahulah kalian?

Haaa.

Awang Sura mengatupkan giginya karena marah sambil mengerling Pak Rombi disamping. Orang tua ini maklum dengan pandangan itu. Memang perkataan Nagasakti itu adalah suatu penghinaan bagi mareka. Keduanya berpandangan dengan muka merah padam dan menahan napas. (KB. KK hal 63-64)

Kutipan [7] di atas bahwa kedewasaan emosi pada segi negatif kita wajib menagtur perasaan kita, sehingga pengungkapannya tidak mengganggu perkembangan kita atau melukai orang lain. Kutipan [7] ini membuktikan bahwa Awang Sura yang tadi sangat marah kepada Mira Nagasakti dapat ditenangkan oleh Pak Lingkur dan tidak terjadi adu fisik hanya bertatap muka saja.

Tabel 4.1

Tabulasi Data Hasil Penelitian Sub Variabel I

\begin{tabular}{|l|l|l|}
\hline \multicolumn{1}{|c|}{ Subvariabel } & \multicolumn{1}{|c|}{ Indikator } & Hasil penelitian \\
\hline 1. Kedewasaan jasmani & a) Kuat & $\begin{array}{l}\text { terjadi cobaan sakitnya seorang anak } \\
\text { menyapu air mata dengan selendang } \\
\text { perahu meluncur seperti anak panah }\end{array}$ \\
& b) Berat & $\begin{array}{l}\text { kerat hati meninggalkan } \\
\text { halaman }\end{array}$ \\
\hline 2.Kedewasaan intelektual & a) Pikiran & $\begin{array}{l}\text { Marilah kita ke istana } \\
\text { bawalah aku ketempatmu }\end{array}$ \\
& b) Pertimbangan & $\begin{array}{l}\text { Dapatlah } \\
\text { permohonan kami } \\
\text { Kami setuju pernikahan kami batalkan }\end{array}$ \\
\hline 3. Kedewasaan emosional & a) Sabar & $\begin{array}{l}\text { Kelum berputus asa } \\
\text { rendah dan beriba-iba }\end{array}$ \\
\hline
\end{tabular}




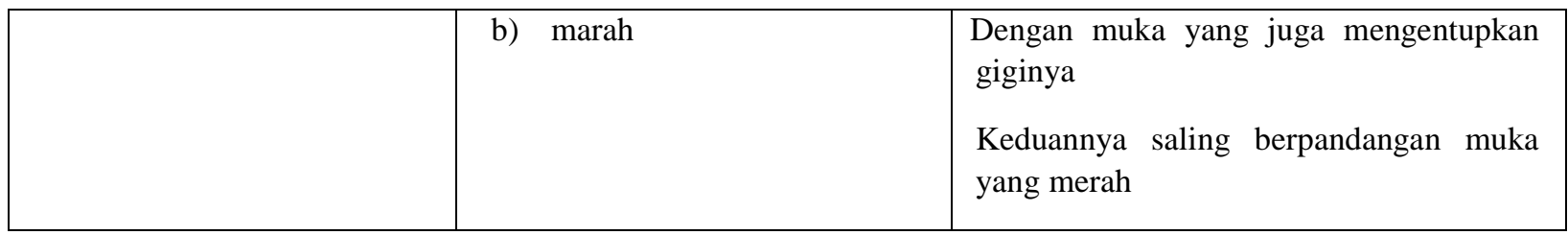

\section{Analisis Proses Kepribadian Tokoh Utama Cerita Rakyat Kehancuran di Baruh Kelayar Karya Anggraini Antemas}

\section{a. Masa kanak-kanak}

Masa kanak-kanak adalah suatu proses perkembangan yang memperbolehkan anak untuk berinteraksi dengan orang lain. Pada masa kanak-kanak adalah masa perkembangan dari usia 2 hingga 6 tahun. Masa itu anak-anak banyak meniru, banyak bermain, dan sandiwara ataupun khayalan, dari masa itu akan memberikan keterampilan dan pengalaman terhadap si anak.

\section{Kutipan [8]}

Kematian si Rombi lima belas tahun yang lalu, memanglah amat memilukan hati, tenggelam dalam danau ketika bersama temannya memancing di danau Kelayar di dekat rumahnya. Sedang yang dapat ditemukan oeleh penduduk yang telah berusaha untuk mencari si Rombi, hanyalah pakaian si Rombi. Sedangkan mayatnya tidak ditemukan orang dan yang mengherankan pula, mengapa baju dan celana si Rombi dalam keadaan utuh. Mungkinkah sebelum tenggelam kedasar danau sempat membuka bajunya itu?. Ataukah mungkin Rombi dibawa oleh mahkluk angker.

Kutipan [8] di atas bahwa masa kanak-kanak ialah dia selalu suka bermain terhadap lingkungannya sendiri. Kutipan [8] ini menggambarkan bahwa Rombi yang dulu masih kanak-kanak iya suka memancing di danau tersebut dan akhirnya Rombi pun meninggal dunia dan adapula yang mengenai Rombi ternyata Rombi belum meninggal dunia hanya saja Rombi dikatakan hilang di ambil dan asuh oleh mahkluk gaib dari dasar danau.

\section{b. Masa Remaja}

Masa remaja merupakan segmen perkembangan individu yang sangat penting, yaitu diawali dengan matangnya organ-organ fisik (seksual) sehingga mampu bereproduksi. Masa remaja adalah masa peralihan dari anak menuju dewasa yang mencangkup kematangan mental, sosial, fisik, pikiran yang berkembang.

\section{Kutipan [9]}

Semakin si Indang dewasa dan besar makin cantik parasnya, tetapi justru iya bertambah terkenang akan abangnya yang sudah lama meninggal itu. Hal inilah yang mengganggu pikirannya, juga mengganggu ketentraman rumah tangga pak Rombi. Tapi walau bagaimanpun, kecantikan wajah Indang Mas tetap menjadi perhatian setiap pemuda, bahkan akhirnya terdengar juga oleh keluarga istana sulakarta.

Tak lama kemudian mereka berempat sampai dikebun buah pak Rombi. Ketika itulah kesempatan bagi Awang Sura untuk berkenalan dengan Indang Mas tersebut. Sambil menikmati manis rambutan, langsat dan habis. Di sinilah mulai kisah percintaan pasangan sejoli ini terjadi. Hubungan ini selalu dipupuknya, sehingga akhirnya 
berkembang rimbun serimbun Tak lama kemudian mereka berempat sampai dikebun buah pak Rombi. Ketika itulah kesempatan bagi Awang Sura untuk berkenalan dengan Indang Mas tersebut. Sambil menikmati manis rambutan, langsat dan habis. Di sinilah mulai kisah percintaan pasangan sejoli ini terjadi. Hubungan ini selalu kebun rambutan si Indang dan berjalan terus menerus dengan penuh sukaria, berjalan lebih panjang dari musim buah. (KB, PK hal 3-5)

Pada Kutipan [9] ini ialah masa remaja masa yang sudah mengalami jauh perubahan dari fisik, dan pula pikir yang semakin berkembang. Pada kutipan [9] di atas menunjukan bahwa Indang Mas ini sudah tumbuh besar dan cantik pula rupanya, hal ini menunjukan bahwa tokoh utama pada Indang Mas ini sudah mengalami masa pobertasnya.

\section{c. Masa Dewasa}

Masa dewasa merupakan periode penyusaian diri terhadap pola-pola kehidupan yang baru dan harapan-harapan sosial baru. Orang dewasa diharapkan memainkan peran baru, suami/instri, orang tua, dan mencari nafkah, dan keinginan-keinginan yang baru.

Kutipan [10]

Dalam istana Sulakarta suasana bergembira ria karena akan menyambut hari perkawinan agung putera mahkota, yaitu antara Awang Sura dengan gadis Indang Mas. Istana Sulakarta dihiasai sedemikian indahnya. Diberikan perhiasaan yang belom pernah ada dalam sejarah daerah tersebut. Senagaja didatangkan ahli-ahli ukir dan juru hias dari luar daerah oleh raja, karena tak mengherankan, bahwa Awang Sura adalah putera tunggal Datuk Temenggung Narodip ayang tersayang.Sesuudah mereka dinikahan secara adat, dan setelah kedua mempelai bersujud kedua orang tua ibu bapaknya masing-masing (Temenggu Narodipa dan Pak Rombi beserta istrinya). Kemudia mareka diarak keliling kampong acara ini dilakukan, selain daripada melaksanakan adat leluruh jaman bahari yang di anut turun memurun juga adalah untuk memenuhi permintaan lapisan masyarakat Sulakarkata, yang memohon agar kedua mempelai diarak keliling kota, melewati lautan manusia yang mencintai putera mahkota kerajaan kesayangan itu. (KB. PK hal 73-74)

Kutipan [10] di atas bahwa masa dewasa ialah masa yang sudah pula pikir bentuk, dan kekuatan untuk maju mencari pasangan hidup sebagai memutivasi kehidupan yang akan datang. Pada kutipan [10] di atas membuktikan bahwa sudahlah smapai Awang sura menikah dengan gadis Indang karena mareka merasakan dirinya sudah dewasa dan mereka berdua pun sudah medapatkan izin dari kedua orang tua masing-masing, disamping itu mereka ingin menjalani kehidupan yang baru. 
Tabel 4.2

Tabel Data Hasil Penelitian Sub Variabel II

\begin{tabular}{|c|c|c|}
\hline Subvariabel & Indikator & Hasil Penelitian \\
\hline \multirow[t]{2}{*}{ 1. Masa kanak-kanak } & a) Bermain & $\begin{array}{l}\text { suka memancing di danau didekat } \\
\text { rumahnya }\end{array}$ \\
\hline & b) Keluarga & $\begin{array}{l}\text { diasuh oleh mahkluk gaib daridasar } \\
\text { danau }\end{array}$ \\
\hline \multirow[t]{2}{*}{ 2. Masa remaja } & a) fisik & Makin besar makin cantik parasnya \\
\hline & b) Mental & $\begin{array}{l}\text { mengganggu ketentraman keluarga } \\
\text { pak Rombi }\end{array}$ \\
\hline c) Masa dewasa & a) Bahagia & $\begin{array}{l}\text { istana sulakarta sangat bergembira } \\
\text { menyambut hari perkawinan angung } \\
\text { putera mahkota } \\
\text { sesuduh dinikahkan mareka diarak } \\
\text { keliling kampong }\end{array}$ \\
\hline
\end{tabular}

\section{SIMPULAN}

Pendekatan psikologi sastra ini sangat besar fungsinya dalam memahami sebuah karya sastra sebagai hasil cipta pengarang. Berdasarkan uraian pembahasan yang telah dikemukakan pada bab terdahulu, maka secara umum $K$ penelitian ini dapat disimpulkan sebagai berikut.

a. Gambaran kepribadian tokoh utama dalam cerita rakyat Kehancuran di Baruhelaya karya Anggraini Antemas meliputi: (a) kondisi kepriba suka memancing di danau didekat rumahnya (b) diasuh oleh mahkluk gaib dari dasar danau dian tokoh meliputi (1) kedewasaan jasmani meliputi (a) terjadinya cobaan sakitnya saorang anak (b) menyapu air mata dengan selendang (c) perahu meluncur seperti anak panah. (2) kedewasaan intelektual (a) Marilah kita ke istana (b) bawalah aku ketempatmu (c) Dapatlah mempertimbangkan permohonan kami (d) Kami setuju pernikahan kami di batalkan (3) kedewasaan emosional (a) belum berputus asa (b) masih meminta dengan suara yang rendah dan beriba-iba (c) Dengan muka yang juga mengentupkan giginya (d) Keduannya saling berpandangan muka yang merah.

b. Gambaran proses kepribadian tokoh utama dalam cerita rakyat Kehancuran di Baruh Kelayar karya Anggraini Antemas meliputi: a) masa kanak-kanak (1) suka memancing di danau didekat 
rumahnya (2) diasuh oleh mahkluk gaib dari dasar danau (b) masa remaja meliputi (1) Makin besar makin

\section{DAFTAR RUJUKAN}

Aminuddin. 2002. Pengantar Apresiasi Karya Sastra. Bandung: Sinar Baru Algensindo.

Antemas, A. 2016. Kehancuran di Baruh Kelayar. Amuntai: Ananda Nusantara.

Endraswara. 2013. Metode Penelitian Sastra. Yogyakarta: CAPT (Center for Academic Publishing Service).

Prawira, P. A. 2016. Psikologi Umum dengan Persefeksi Baru. Yogyakarta: Ar-Ruzz Media.

Ratna, N. K. 2004. Teori, Metode dan Teknik Penelitian Sastra. Reality Publisher.

Sugono, D. 2003. Buku Praktik Bahasa Indonesia. Jakarta: Depertemen Pendidikan Nasional.

Sobur, A. 2009. Psikologi Umum. Bandung: Pustaka Setia. 